\title{
Jóvenes de origen extranjero y participación social. ¿Diferentes procesos migratorios conducen a diferentes modelos de participación?
}

\author{
David Dueñas i Cid \\ Universitat Rovira i Virgili \\ david.duenas@urv.cat
}

Resumen: Diversos autores coinciden en señalar la participación social como un elemento central en la integración de la población inmigrada. Los jóvenes inmigrantes, como grupo específico, presentan una importante beterogeneidad interna, no sólo en cuanto a origenes culturales o geográficos, sino también en relación con las características del proceso migratorio vivido que, además, configuran perfiles comunes que articulan grupos con problemáticas similares en relación a la participación. El objetivo de este artículo es analizar estos elementos comunes $y$ diferenciales entre los distintos grupos de jóvenes en función de las condiciones de su proceso migratorio.

Palabras clave: juventud, migración, participación social, asociacionismo, participación ciudadana

Abstract: Many authors consider social participation to be a key feature of immigrant integration. Young migrants form specific social groups that have considerable internal heterogeneity, not only because of their cultural or geographical origins, but also because of the similarities of their migration process. However, although they belong to different groups, they have similar problems of social participation. The main aim of the paper is to analyze the features that are common to various groups and those that are different on the basis of the conditions of their migration process.

Keywords: youth, migration, social participation, associationism, citizen participation 


\section{Introducción}

Este articulo aborda de forma sintética la relación entre las personas de origen extranjero y la participación social, entendiendo esta relación a partir de la definición de la participación como «aquellas acciones que los individuos llevan a cabo con voluntad de incidir en la configuración de la vida colectiva» (González et alii, 2007: 11). Esta definición, conscientemente amplia, tiene la voluntad de integrar los distintos tipos de participación social en los que la población de origen extranjero interviene o aspira a hacerlo: la participación ciudadana en procesos impulsados por las instituciones, la participación electoral y la participación en asociaciones o actividades.

Si bien estos tres tipos de participación comparten tanto el objetivo final de permitir que la ciudadanía pueda incidir en la toma de decisiones, como su clasificación teórica dentro de la participación individual institucionalizada (Ganuza, 2008), las formas que plantean para conseguirlo difieren tanto en las formas como en el fondo. En relación con la participación ciudadana en procesos impulsados por las instituciones públicas, puede ser entendido teóricamente como un ejercicio de corresponsabilidad entre la sociedad y las instituciones para favorecer la toma de decisiones colectivas conjuntas, de modo que las políticas de fomento de la participación ciudadana devienen herramientas fundamentales para mejorar el diseño, evaluar los servicios y detectar las necesidades reales de la población (Subirats, 2007: 57). Estos procesos persiguen un objetivo doble vinculado con la dimensión política de la participación social: por un lado vinculan al individuo con el colectivo, la participación ciudadana favorece el empoderamiento de la ciudadanía y la incorpora en los procesos de toma de decisiones; por otro, permite ampliar el abanico de opciones a considerar en estos procesos, visibilizando aquellas opiniones minoritarias que, en condiciones normales, quedan ocultas bajo la normalidad y, por lo tanto, mejora la información disponible para la gestión pública.

La participación electoral, en cambio, es un modelo de participación individual, directa (Serrano, J. y Sempere, D., 1999) y vinculada a los derechos de ciudadanía que, si bien los discursos redundan en la constatación del aumento de la abstención y el análisis de sus motivos en España (Justel, M., 1990; Boix, C. y Riba, C., 2000; Delgado, I., 2010) y, por extensión, en el resto de las democracias occidentales, es ampliamente considerada como el mejor método para gestionar el gobierno estatal (Catt, 1999). En este ámbito, y vinculado a la situación jurídica de cada individuo de origen extranjero, se puede establecer una segmentación de la población entre aquellos que tienen derecho a voto ${ }^{1}$, ciudadanos comunita-

1 Restringido, únicamente, para las elecciones municipales y, en el caso de los ciudadanos originarios de países 
rios y otros que, en virtud de criterios de reciprocidad con el derecho a voto de la inmigración española en sus países de origen, pueden disponer, también, del mismo derecho en España ${ }^{2}$; y aquellos que no tienen reconocido este derecho. Ante esta dualidad, y ante el hecho de que el derecho a voto va asociado al derecho a la "ciudadanía", «categoría política que [...] expresa la pertinencia a una comunidad política concreta» (Ortega, A. y Heredia, L. 2008), la situación de discriminación legal de las personas originarias de numerosos otros países en España impide una plena integración de los mismos en el territorio.

En tercer lugar, el asociacionismo aparece como un tercer elemento de articulación de la acción colectiva que permite enlazar al ciudadano individual, a partir de su vinculación con el movimiento asociativo, con las instituciones públicas. Las asociaciones juegan el papel de institución «mesosocial» (Kwak et alii, 2009) en tanto que vinculan a colectivos con situaciones similares en un contexto que facilita el desarrollo de una acción colectiva que responda a los intereses comunes de sus asociados, y que acarrea un impacto sobre las instituciones públicas superior al que puede conllevar la suma de las acciones individuales. En este sentido, Warren (2001) plantea tres grandes efectos de la práctica asociativa: los efectos de desarrollo (transmisión de información, desarrollo de habilidades políticas o incremento de niveles de confianza en el ejercicio de los derechos políticos), la creación de espacio público (lo que permite crear espacios de debate acerca de temas propios del colectivo asociado) y los efectos institucionales (lo que permite a las asociaciones la interacción con las instituciones). El papel de las asociaciones en relación con la inmigración es, pues, el de complementar los elementos de organización informal de las personas de origen inmigrado con espacios de organización formal (Casey, 1998) con unas funciones distintas y un alcance de las mismas que trasciende la individualidad.

En este sentido, resulta pertinente el análisis de la participación social a partir de la revisión de la participación ciudadana, electoral y asociativa, entendiendo que son formas de relación que permiten la ampliación de la noción de ciudadanía desde el ámbito municipal (De Lucas, 2009), sin necesidad de plantear cambios en ámbitos de gestión superiores que, probablemente, resulten más complicados y no respondan con la celeridad necesaria a las transformaciones sociales. En la misma línea, resulta interesante ahondar en el papel de la participación social como elemento de integración sobre la base de la potencialidad de dichos procesos para vincular distintos actores sociales individuales y colectivos, actividad

miembros de la Unión Europea (UE), también en las europeas.

2 A principios de 2011, los países no comunitarios cuyos habitantes tienen el derecho a voto reconocido para las elecciones municipales son: Argentina, Bolivia, Burkina Faso, Cabo Verde, Chile, Colombia, Corea del Sur, Ecuador, Islandia, Noruega, Nueva Zelanda, Trinidad y Tobago, Uruguay, Paraguay, Perú y Venezuela. 
necesaria y relevante entendiendo la situación de revisión del capital social que acompaña al proceso migratorio (Hagan et alii, 1996). Estos elementos elevan la idea de la participación social de la población inmigrada a un objetivo individual y colectivo en el migrante, que facilita la re-creación del capital social así como la integración de la ciudadanía, pero que también se convierte en un objetivo institucional, tal como plantea Herzog (Herzog et alii, 2009), en tanto que elemento de mejora estructural del funcionamiento del sistema.

Del mismo modo que, a escala teórica, el fomento de las políticas de participación social parece un objetivo interesante, en el ámbito legal se sientan las bases para favorecer su implementación. La Constitución Española, en su artículo 9, apartado 2 , recoge que «corresponde a los poderes públicos promover las condiciones para que la libertad y la igualdad del individuo y los grupos en que se integra sean reales y efectivas, remover los obstáculos que impidan o dificulten su plenitud y facilitar la participación de todos los ciudadanos en la vida política, económica, cultural y social»; y en el artículo 22 , apartado 1 , se reconoce el «derecho de asociación», bajo unas condiciones reformuladas el año 2002 (Ley Orgánica 1/2002). En una línea parecida se manifiesta la Carta Europea de Salvaguarda de los Derechos Humanos, que también recoge el derecho a la participación y la asociación (artículo VIII, apartados 1 y 2).

Por el contrario, y a pesar de las potencialidades planteadas en relación con la participación social de la población inmigrada, Malgesini (2007) ofrece una serie de elementos que dificultan o condicionan la participación social efectiva de este colectivo y, a la postre, redundan en la complejidad del proceso de integración de la población extranjera. Estos elementos son: los discursos generalizadores que se dan alrededor de la inmigración, las actitudes de los grupos de iguales, las dificultades con el idioma, las características del proyecto migratorio, las características en la socialización del individuo, el temor a la mayor visibilidad, las dificultades que supone el proceso de reagrupación en la aceptación de la inmigración o las limitaciones relacionadas con la dificultad de conciliar la vida laboral y personal (la incorporación al mercado laboral y la maternidad o las cargas familiares en edades más jóvenes; trabajos con intensas exigencias de tiempo; ausencia o debilidad de las redes de apoyo o menor tradición de participación pública femenina).

Otro elemento que dificulta la función integradora de la participación social, en este caso centrado en el asociacionismo, es el difícil equilibrio entre las dos funciones básicas de cualquier entidad asociativa: mecanismos internos y externos (Moreras, 2009), o, utilizando la terminología propuesta por Putnam (2000), bridging y bonding. El trabajo interno (bonding) de una asociación consiste en el trabajo necesario para vincular internamente todos aquellos miembros de una 
entidad, a partir del contacto interpersonal y el fortalecimiento de relaciones con la creación de sentimientos de pertenencia comunes y de confianza respecto del papel cohesionador de la asociación. El trabajo externo (bridging) vincula la entidad con su entorno inmediato (sociedad de acogida e instituciones). Esta doble función de las asociaciones puede poner de relieve una discordancia de objetivos entre las instituciones públicas - que pueden tener un mayor interés en promocionar la función externa de estas asociaciones como forma de integración-y las propias asociaciones - que pueden tener una mayor facilidad para trabajar internamente con los miembros del grupo de iguales, fomentando actividades culturales tradicionales de los países de origen o facilitando el mantenimiento de la lengua propia en las nuevas generaciones.

\section{Metodología ${ }^{3}$}

Desde un punto de vista metodológico, se parte de la premisa de que el estudio de las necesidades y las demandas de la población joven de origen inmigrante supone ahondar en una realidad que se caracteriza por su importante heterogeneidad. En relación a la heterogeneidad de la población objeto de estudio, se ha diferenciado entre aquellas personas que han migrado a Cataluña por decisión propia de aquellos grupos de jóvenes, hijos e hijas de inmigrantes que han llegado a Cataluña, o han nacido ya aquí, en el marco de un proyecto migratorio familiar. A partir de esta distinción, se han creado tres grupos en función de la situación generacional respecto al proyecto migratorio y el momento de llegada. Grupo 1: Jóvenes con proyecto migratorio propio, llegados con más de 18 años. Grupo 2: Jóvenes hijos e hijas de inmigrantes nacidos en Cataluña o llegados durante la infancia (menos de 10 años), que han desarrollado la mayor parte del proceso educativo en el país de acogida. Grupo 3: Jóvenes hijos e hijas de inmigrantes llegados a Cataluña entre el final de la infancia (10 años) y la mayoría de edad (18 años), y que han desarrollado una educación dual: país de origen - país de acogida

Para estos tres grupos, se ha considerado como población objeto de estudio los y las jóvenes de entre 16 y 29 años, excluyendo aquellos que proceden de los países más desarrollados, pero incluyendo los procedentes de Europa del Este. Por otro lado, el diseño de la investigación se ha apoyado en técnicas cualitativas de producción de información, tal como recoge la siguiente figura:

$3 \mathrm{El}$ presente artículo es parte de los resultados de la investigación «Joves d'origen immigrant a Cataluña. $\mathrm{Ne}$ cessitats i demandes: Una aproximació sociològica», realizada gracias a la financiación del Observatori Català de la Joventut (Secretaria de Joventut) de la Generalitat de Cataluña 
Figura 1. Resumen de la metodología y del trabajo de campo

\begin{tabular}{|c|c|c|c|c|}
\hline $\begin{array}{l}\text { Situación general } \\
\text { de Cataluña. }\end{array}$ & \multicolumn{4}{|c|}{$\begin{array}{l}\text { Análisis bibliográfico y de informes previos. } \\
\text { Análisis de la legislación. } \\
\text { Análisis estadístico de fuentes secundarias referentes a las } \\
\text { características del territorio y de la población juvenil de origen } \\
\text { inmigrante. } \\
\text { Análisis de la Enquesta de Participació, Política i Joves (2006), } \\
\text { con una amplia muestra del colectivo inmigrante. }\end{array}$} \\
\hline Situación municipal & \multicolumn{4}{|c|}{$\begin{array}{l}\text { Análisis de los Planes Locales de Juventud y de los Planes de } \\
\text { Ciudadanía y de Inmigración de } 10 \text { municipios. } \\
\text { Entrevistas con } 10 \text { técnicos de juventud y de inmigración de } \\
\text { estos municipios. }\end{array}$} \\
\hline $\begin{array}{l}\text { Profundización en la } \\
\text { situación municipal }\end{array}$ & Municipio 1 & Municipio 2 & Municipio 3 & Municipio 4 \\
\hline \multirow{4}{*}{$\begin{array}{l}\text { Sobre necesidades } \\
\text { y demandas }\end{array}$} & \multicolumn{4}{|c|}{$\begin{array}{l}16 \text { entrevistas a jóvenes usuarios de equipamientos, } 4 \text { por } \\
\text { municipio. }\end{array}$} \\
\hline & \multicolumn{4}{|c|}{12 grupos de discusión con jóvenes usuarios, 3 por municipio. } \\
\hline & \multicolumn{4}{|c|}{$\begin{array}{l}4 \text { grupos de discusión con responsables de los servicios, } 1 \text { por } \\
\text { municipio. }\end{array}$} \\
\hline & \multicolumn{4}{|c|}{10 entrevistas biográficas, $2-3$ por municipio. } \\
\hline $\begin{array}{l}\text { Análisis de la } \\
\text { tipología de servicios } \\
\text { y recursos disponibles } \\
\text { de su funcionamiento. }\end{array}$ & \multicolumn{4}{|c|}{$\begin{array}{l}16 \text { equipamientos de formación, trabajo, ocio, cultura y } \\
\text { deporte, } 4 \text { por municipio. }\end{array}$} \\
\hline
\end{tabular}

Fuente: Alarcón y Alcalde (2010).

En relación con la distribución territorial de la investigación, se ha centrado en Cataluña desde una perspectiva municipal. Para ello se ha planteado una distribución de municipios representativa, con 10 municipios en una primera fase para profundizar posteriormente en la realidad municipal en otros 4 municipios en una segunda fase. Para la elección de los municipios se han considerado, como variables de homogeneidad, la existencia de un Pla Local de Joventut (Plan Local de Juventud) y la representación de población joven de origen extranjero, mientras que, como criterios de variabilidad, se han considerado el tamaño poblacional y la diversidad geográfica de origen de la población objeto de estudio.

En total, participaron en el trabajo de campo 104 jóvenes en las entrevistas biográficas y los grupos de discusión, distribuidos de la siguiente manera: 10 en las entrevistas biográficas, 16 en las entrevistas en los equipamientos y 80 en los grupos de discusión. También participaron 49 técnicos con la siguiente distribución: 23 de distintas áreas municipales en contacto directo con la prestación 
de servicios a jóvenes de origen inmigrante, 10 de las áreas de juventud de los ayuntamientos y 16 responsables de equipamientos municipales. A escala documental se analizaron los Plans Locals de Ciutadania i Immigració (Planes Locales de Ciudadanía e Inmigración), así como los Plans Locals de Joventut de estos municipios.

Finalmente, y en relación con los contenidos estudiados, estos se concretan en tres puntos básicos que se desarrollan para cada grupo teórico planteado. En primer lugar, las formas de participación de la población de origen inmigrante y el conocimiento que demuestran acerca de los canales existentes para desarrollarla. En segundo lugar, la identificación de las demandas y necesidades insatisfechas en relación con la participación social. Por último, las dificultades y fortalezas de la participación de cada grupo concreto.

\section{Principales resultados}

\subsection{Grupo 1: Jóvenes extranjeros con proyecto migratorio propio}

\subsubsection{Distinción de las formas de participación y conocimiento de los canales}

A modo de introducción, podemos diferenciar entre la participación formal o promovida por la Administración que se concreta en la participación electoral y ciudadana, un canal informal o basado en la red social del individuo, centrada en el asociacionismo o en la participación individual en actividades. A partir de la observación empírica, los jóvenes extranjeros con proyecto migratorio propio utilizan principalmente los canales informales de participación y, en ocasiones, a partir de éstos, acaban accediendo a los canales formales. Esta constatación nos remite a la idea anteriormente planteada acerca de la importancia de la función externa del movimiento asociativo como herramienta de integración. En este sentido, cabe resaltar la importancia del grupo de iguales como facilitadores del acceso a las asociaciones.

Los canales formales de participación, por su parte, resultan ampliamente desconocidos tanto en lo que se refiere a su funcionamiento como a la forma de acceder a ellos, en tanto que, a pesar de los esfuerzos desarrollados por parte de las administraciones para protocolizar y planificar la participación ciudadana ${ }^{4}$, muchos municipios catalanes presentan una importante carencia a la hora de

4 La idea que desde las administraciones catalanas se ha intentado impulsar, en relación con la participación ciudadana, es que ésta no debe ser improvisada sino que debe partir de la planificación y la protocolización mediante cuerpos metodológicos e instrumentos técnicos que permitan la consolidación de esta forma de trabajar en la administración local (Martí y Rebollo, 2007). 
llevarla a cabo, lo que dificulta la consolidación de las metodologías participativas como elemento importante en la gestión pública. Entre la población extranjera con proyecto migratorio propio, este desconocimiento resulta más destacado porque a las dificultades propias de la Administración para llevarla a cabo, hay que añadir la propia situación de los individuos, lo que comporta que sea muy difícil que su acceso se produzca de forma normalizada.

Para facilitar el acceso a la participación formal, e incidiendo también sobre la informal, la mayoría de administraciones locales de nuestra muestra intentan llevar a cabo diferentes sistemas para ofrecer un mayor conocimiento del municipio a la población de origen inmigrante. Estos sistemas van desde la publicación de materiales de difusión en distintos idiomas que recojan la información básica del municipio, hasta la atención personalizada a la nueva ciudadanía, desarrollada a partir de los propios técnicos de inmigración o mediante agentes especiales de integración.

La tarea de estos agentes es informar al ciudadano recién llegado y orientarlo acerca de las dudas que pueda tener, ofreciéndole información sobre los distintos canales de participación formal e informal que dispone el municipio. Este trabajo, por tanto, supone un primer paso en la re-creación del capital social de la población inmigrada, en tanto que la información aportada suele incluir referencias acerca de las asociaciones de inmigrantes en las que puede participar, o, incluso, poner a las personas en contacto con otras de orígenes geográficos o culturales similares, facilitando la primera acogida de estas personas en el municipio.

De todos modos, a pesar de los esfuerzos para facilitar la acogida por parte de las administraciones, la forma de relación social de los jóvenes extranjeros con proyecto migratorio propio está basada en la informalidad, en el contacto con el grupo de iguales que se configura a partir de su interacción diaria. En este contexto, $y$ asumiendo que el grupo de iguales puede ser un canal que permita al individuo conocer la existencia y funcionamiento de las asociaciones de inmigrantes, y, a partir de ello, pueda plantearse su incorporación a las mismas, las prácticas de acogida juegan un papel importante en la incorporación de los individuos al tejido asociativo, ya que ponen en contacto actores distintos por cuestiones de practicidad funcional: es más fácil para la Administración la relación con la ciudadanía asociada que con la no asociada. 
3.1.2 Identificación de las demandas en relación a la participación y las necesidades insatisfechas.

Las demandas expresadas por los jóvenes participantes en la investigación ${ }^{5}$ guardan mucha relación con la participación informal y con el consumo de actividades, y muestran escasa inclinación hacia la participación formal, del mismo modo que están directamente relacionadas con el tiempo de convivencia en el territorio o el municipio. Si bien en un primer momento las demandas de participación se vinculan con aquellas actividades que favorecen la creación de una red de contactos, a medida que pasa el tiempo su vinculación con las actividades que se llevan a cabo en el municipio va aumentando gradualmente, sobre todo en tres ámbitos: ocio, deporte y cultura.

Las actividades de ocio y cultura más solicitadas son la realización de fiestas, especialmente por parte de aquellos que llevan poco tiempo en el territorio, así como cursos de lengua o actividades de refuerzo cultural de la cultura de origen. Muchas de estas actividades se canalizan a través de las asociaciones — actividad que enlaza con las actividades de refuerzo interno del sentimiento de pertenencia al grupo de iguales (bonding) - y, en el caso de municipios con una duradera tradición migratoria de colectivos concretos, o en los que hay una intensa relación entre alguna asociación concreta y las instituciones locales, estas actividades llegan a institucionalizarse y se organizan de forma conjunta entre estos dos agentes. Este hecho conlleva la superación del contenido lúdico o festivo, al incorporar elementos educativos y de fomento de la convivencia con la población autóctona para intentar sensibilizar acerca de las diferentes realidades presentes en el municipio.

Por otro lado, las actividades vinculadas con el deporte presentan sensibles diferencias en relación a lo comentado acerca de las culturales, en tanto que no suele existir una relación directa entre las asociaciones y las instituciones, por lo que los equipamientos deportivos públicos quedan infrautilizados por parte de la población de origen inmigrado, que utiliza, en mayor medida, espacios no preparados para su uso deportivo o los gimnasios privados.

El hecho de que estas actividades se lleven a cabo por parte de jóvenes extranjeros con proyecto migratorio propio está mediatizado por dos principios básicos: el precio de la actividad y el grado de formalidad que requiere. A escala técnica se insiste mucho en esta idea: las actividades gratuitas tienen mucho más éxito que aquellas cuya realización conlleva un determinado gasto económico, lo que genera un problema práctico; se trabaja para ofrecer actividades al menor

5 Tanto los jóvenes extranjeros con proyecto migratorio propio, como los socializados en Cataluña y los que han sido reagrupados. 
coste posible, pero se dan enormes dificultades para conseguir los recursos que permitan rebajar su precio ${ }^{6}$. El grado de formalidad, en segundo lugar, también supone un elemento importante a tener en cuenta, puesto que aquellas actividades de carácter puntual e informal suelen resultar más atractivas que las que requieren más tiempo o regularidad.

[Técnica] Como más abiertas son, más participan; pero a mayor formalidad, menor participación.

Estos dos factores condicionan la oferta de actividades, puesto que muchos técnicos intentan fomentar las actividades que reúnan estas condiciones (concursos de PlayStation, torneos de fútbol, jornadas festivas, etc.) como primer paso para alcanzar una mayor vinculación en actividades mas extensas.

En relación con el deporte, la forma en la que tradicionalmente se han organizado en Cataluña estas actividades resulta poco atractiva para muchos de los jóvenes de este grupo. En el caso de los deportes de equipo (fútbol, baloncesto, críquet, etc.), su práctica se basa en la espontaneidad y se practica por grupos de nacionalidad, que organizan partidos improvisados en espacios públicos ${ }^{7}$.

[Técnico] Si montas una actividad abierta a todos, no reglada, participan muchísimo [...], si un día montas unas porterías de 3x3 o un campo de césped artificial, participarán muchísimo. En cambio, quizá una cosa con más compromiso, que compromiso puede implicar estar federado, ir a entrenar, los fines de semana, no sé qué... cuesta más.

La gestión de las actividades deportivas en Cataluña, por el contrario, está mucho más vinculada a la regularidad en su práctica, a partir de la vinculación a entidades deportivas. Este hecho incide en que, a pesar de que la participación en actividades deportivas sea una demanda importante, no se consiga una vinculación de estos jóvenes con las actividades que se coordinan desde los servicios deportivos.

[Técnico] El deporte, sí que les gusta, tienen interés en saber qué se hace en las instalaciones deportivas... pero les cuesta mucho...

6 Cabe destacar que la investigación se desarrolló en un momento muy inicial de la crisis económica que actualmente (2011) afecta a España, de modo que se presupone que las dificultades para abaratar las actividades no habrán disminuido, sino que, al contrario, serán superiores.

7 Se aprovechan los campos de fútbol y baloncesto de las escuelas o los parques públicos, sobre todo durante las tardes o fines de semana, para la organización espontánea de partidos entre la población extranjera. 
La participación formal a partir de la inclusión en el sistema electoral local también constituye una demanda de los jóvenes extranjeros con proyecto migratorio propio, aunque de forma casi exclusiva por parte de aquellos que están vinculados a las asociaciones de inmigrantes. El papel de estas entidades como orientadoras y canalizadoras de las necesidades permite que aparezcan demandas que transmiten una conciencia colectiva, que supera las demandas meramente individuales.

$\mathrm{Y}$ a vosotros, ¿os gustaría participar en política?

[M, 25, Senegal, casada, Grupo 3] Sí que nos gustaría tener el derecho a votar en las elecciones.

[M, 30, Bulgaria, casada, Grupo 2] Quiero decir, como vivimos aquí, tenemos las leyes como para catalanes, como para españoles, y está bien para nosotros, entonces, las cosas se mejoran mejor, se cobra más...

[M, 25, Senegal, casada, Grupo 3] Tenemos los mismos deberes que los catalanes, pero los derechos, no...

Este interés en la participación electoral se visibiliza a partir del conocimiento que los jóvenes poseen sobre la política, aunque con una diferencia importante. En general, demuestran tener un conocimiento suficiente acerca del espectro político español, en cuanto a las personas que se presentan y las ideas que defienden, que no es equiparable al que poseen en cuanto al ámbito catalán o municipal; tan sólo aquéllos que mantienen una relación habitual con la Administración conocen a los alcaldes de los municipios.

\subsubsection{Dificultades y fortalezas de la participación.}

Partimos de Malgesini (2007) para analizar las principales dificultades que afectan a los jóvenes extranjeros con proyecto migratorio propio. Agrupamos las dificultades en función de sus características: individuales y estructurales. En primer lugar, en lo que refiere a las dificultades individuales, las más repetidas son el idioma y el trabajo, aunque también cabe incluir las expectativas que el joven pueda tener en relación con su participación, expectativas que pueden facilitar o dificultar su participación misma a partir de experiencias previas individuales o aquellas que pueda haber conocido a partir de su red social.

Respecto a la vinculación con el mercado laboral, si entendemos que el componente económico es primordial en la gran mayoría de migraciones contemporáneas, resulta lógico concebir que la principal preocupación sea el acceso norma- 
lizado al mercado laboral y la obtención de ingresos que permitan la subsistencia. Esta idea la repiten constantemente los técnicos que han colaborado en el estudio como uno de los elementos centrales que dificultan la participación.

[Técnico] Supongo que su principal preocupación es el trabajo, que les absorbe mucho tiempo, y creo que dejan la participación como una cosa que no va con ellos.

[Técnico] Hasta que no hay trabajo, no hay red... un poco establecido en las cosas básicas, no se plantean la participación

En segundo lugar, aparece el idioma, ya que a la persona extranjera le resulta difícil entender las informaciones, carteles, cartas $u$ otros procedimientos tradicionales de comunicación de la Administración. En este contexto se abre un debate acerca de la política lingüística interna de la Administración para referirse a este público; si bien es cierto que todos los técnicos entrevistados comparten la idea de que el catalán es y debe ser la lengua de uso de la Administración catalana, esta apuesta política genera problemas prácticos que se podrían mitigar con el uso de otras lenguas presentes en el territorio (árabe, rumano, español, etc.), lo que supone iniciar un debate que sobrepasa las capacidades de la Administración local y que no presenta una solución satisfactoria para todos los implicados.

[Técnico] (la participación) les queda muy lejos, puede ser por el idioma y estas cosas...

[Técnica]El plan local nos lo encontramos (así), «claro que nosotros no entendemos cuando vemos un cartel colgado y está en catalán», y ¿qué haces? ¿Tienes que colgarlo en todos los idiomas? Claro, no sé... (...) nosotros montamos una actividad, consideramos que la difusión hay que hacerla en catalán, y se lo pasamos a la (técnica), y ella, a partir de las sesiones de acogida, lo difunde...

Así pues, resulta evidente la importancia del idioma como elemento importante para la participación, pero esta dificultad tiene, también, un efecto positivo sobre la relación con las asociaciones de connacionales, en tanto que vehiculan sus necesidades a través de estas entidades, que juegan el papel de mediadoras idiomáticas.

Finalmente, cabe destacar que las expectativas individuales respecto a la participación pueden mostrar un papel ambivalente. Una percepción positiva en relación a la utilidad de intervenir socialmente, sea mediante la participación en actividades, procesos participativos o colaborando con entidades, favorecerá la posibilidad de que esto ocurra. Por el contrario, una percepción negativa la perju- 
dicará. En este contexto, si entendemos que los canales informativos que inciden en la población joven extranjera con proyecto migratorio propio suelen ser los informales (boca-oreja), una percepción negativa por parte de algún miembro de la red de relaciones del individuo puede transmitirse por toda la red, perjudicando así la percepción del conjunto.

En lo que refiere a los problemas estructurales, se pueden resumir en las dificultades heredadas a partir de las condiciones de socialización del individuo en el país de origen o en el de acogida, así como en las dificultades prácticas del proceso participativo. En primer lugar, muchos países tienen una marcada carencia de tradición participativa y, en algunos casos, incluso democrática, mientras que las formas de expresión asociativa en los países de origen pueden seguir, en algunos casos, unos parámetros que se alejan de los que se dan en Cataluña. En este sentido, la persona que a partir de su proceso de socialización ha adoptado una posición activa en las prácticas de cogestión o, al menos, de vinculación con la res pública en su país de origen, intentará desarrollarlas también en el país de acogida, aunque cabe reconocer que este grupo resulta minoritario. La situación general, por el contrario, es que el proceso de socialización en origen de la población joven con proyecto migratorio propio no suele favorecer actitudes participativas en el país de acogida, por lo que resulta complicado implicarlos en procesos participativos formales.

Finalmente, cabe mencionar la relación de la población inmigrada con el mundo asociativo. Del mismo modo que, en general, se considera que a una persona inmigrada le beneficia el hecho de encontrar personas connacionales entre la población de acogida, en tanto que facilita el primer contacto - esta es una de las funciones básicas de las asociaciones de inmigrantes-, el hecho de compartir nacionalidad también conlleva que se arrastren problemas propios del país de origen al seno de la asociación, como pueden ser las tensiones nacionalistas o las diferencias religiosas. En nuestro trabajo de campo se observa, en el caso de la población de origen rumano, una de las más numerosas en el territorio, que esta problemática aparece claramente entre la población que proviene de la zona cercana a Moldavia y la del resto de Rumanía, que acaban trasladando este problema a la dinámica de funcionamiento de la asociación. En uno de los casos analizados, el que la dirección de la entidad de ciudadanos rumanos recaiga en un miembro de un determinado colectivo, condiciona la relación que entabla con los miembros de otro de los colectivos, que se sienten mal representados por la entidad, lo que reduce, consecuentemente, el interés por vincularse con la misma. Éste es un hecho relevante en tanto que las instituciones públicas utilizan a menudo las entidades como interlocutores válidos para relacionarse con las personas 
de determinado origen presentes en el municipio, por lo que las deficiencias en la gestión de las asociaciones invisibilizan a una parte de sus teóricos miembros.

Por lo que respecta a las fortalezas, se pueden agrupar del mismo modo en función de si son individuales o estructurales. A escala individual, la necesidad de crear una nueva red social en el municipio de acogida es el principal elemento que incide sobre la participación. El papel que juega la importante red de asociaciones de población inmigrada presente en el territorio es un elemento básico para mediar entre los individuos y la Administración encargada de gestionar los procesos de participación. Por otro lado, el hecho de que existan amplias comunidades de población extranjera en el territorio facilita la aparición de personas que dispongan de las habilidades y voluntades necesarias para trabajar en la coordinación del resto de población inmigrada mediante las asociaciones, con el impulso de las administraciones locales ${ }^{8}$.

Cabe destacar, también, la tradición existente en el fomento del asociacionismo y el importante esfuerzo que se ha realizado por parte de las administraciones catalanas para fomentar dinámicas de participación ciudadana. En este sentido, el fomento del asociacionismo está consolidado en las administraciones locales, quienes destinan tiempo y recursos al trabajo con estas entidades hasta el punto de que, en algunos municipios, se suplen las carencias de personal técnico con un fomento de la colaboración entre administraciones y asociaciones.

Finalmente, la continua presencia de procesos migratorios en Cataluña ha facilitado la consolidación de un amplio tejido asociativo inmigrante y de «expertos» en la orientación de la ciudadanía recién llegada en el seno del mismo tejido.

\subsection{Grupo 2: Los jóvenes socializados en Cataluña}

\subsubsection{Distinción de las formas de participación y conocimiento de los canales}

En el caso de los jóvenes socializados en Cataluña, el conocimiento de los canales de participación es relativamente equiparable al que puede tener la población autóctona.

¿Qué se imaginan ustedes cuando alguien así como yo les dice, vamos a hablar de participación? ¿Qué se imaginan?

8 El número de asociaciones de población marroquí, por ejemplo, ha aumentado de 170 a 297 desde el año 2000, coincidiendo con el aumento de población de este origen (Moreras, 2009). 
[H, 16, Marruecos, soltero, grupo 2] Ni idea

[M, 17, Gambia, soltera, grupo 2] Ir a votar

El hecho de haberse educado íntegramente en el sistema educativo catalán comporta un conocimiento de las herramientas que permiten desenvolverse con normalidad en Cataluña, sobre todo en lo que se refiere a la formación de una red social diversa, la adquisición de conocimientos idiomáticos y la participación habitual en actividades en el contexto educativo. Del mismo modo, el que los jóvenes socializados en Cataluña hayan pasado por el sistema educativo supone para los técnicos un hecho diferencial respecto del resto de población de origen inmigrante, a pesar de que manifiestan abiertamente sus recelos hacia el sistema educativo en lo referente a la creación de «ciudadanos y ciudadanas».

La educación que reciben estos jóvenes juega un papel muy importante en las expectativas sobre sus futuras posibilidades como miembros de la sociedad catalana, en tanto que el paso por el sistema educativo resulta de capital importancia para su integración, permite la interiorización de las normas de convivencia y constituye un espacio de igualdad entre los alumnos y, de manera indirecta, también entre los padres y las madres. Éstos también pueden encontrar en el sistema educativo un espacio de interacción que los vincula con otros padres y madres de orígenes distintos. La escuela se convierte en un elemento socializador de primer orden en la vida de la persona inmigrada y de sus familiares cercanos, pero aun así transmite debilidades a la hora de formar ciudadanos participativos y comprometidos; por esto resulta necesario fomentar e impulsar los espacios de toma de decisiones por parte de los alumnos en los centros educativos, de modo que, aparte de interiorizar los conocimientos necesarios para su formación, puedan también aprender las habilidades necesarias para su participación tanto en aquellos procesos propuestos por las administraciones como en defensa de sus derechos como ciudadanos.

Aparte de las funciones formativas del sistema educativo, tanto su funcionamiento administrativo como la oferta de actividades que propone incitan a los padres y madres a familiarizarse en el trato con la Administración y con otros padres y madres. Este hecho favorece que algunas instituciones locales utilicen las escuelas como «altavoces» para hacer llegar determinadas informaciones relevantes a las familias.

[M, 26, Argentina, casada, grupo 1] No lo sé... En el cole, a los niños sí que lo hacen (informarlos). Porque llegan en septiembre con papeles, papeles, papeles... cada día... de todas las actividades que pueden hacer... 
De todos modos, una vez que los padres están informados acerca de las actividades y posibilidades de sus hijos, su aprovechamiento viene determinado por otros condicionantes, entre los que destacan los económicos y los culturales. Los responsables de las escuelas que participaron en la investigación manifiestan que realizan grandes esfuerzos para intentar que todos los niños y niñas puedan participar en las actividades que se desarrollan, pero, según sus relatos, el componente económico aparece frecuentemente como un elemento que determina si las pueden realizar o no.

Otro de los elementos que forman el currículum oculto del sistema educativo vincula al individuo con su socialización en el entorno en el que vive, lo que le permite entrar en contacto con el grupo de iguales, donde cada individuo teje su propia red social individual. El hecho de que los jóvenes socializados en Cataluña puedan disponer de una red social distinta de la de sus padres, en la que el elemento común sea la edad y las vivencias compartidas, y no el origen étnico o cultural, puede favorecer la satisfacción de ciertas necesidades, renovando así, por ejemplo, el papel de las asociaciones de inmigrantes en relación con estos inmigrantes de segunda generación a partir de plantear la utilidad o inutilidad de un elemento central de dichas asociaciones: permitir el contacto entre connacionales, re-creando tejidos sociales. Se relativiza, así pues, la importancia del componente cultural como eje central del asociacionismo, a partir de la mezcla de elementos culturales de la cultura de origen y la de acogida, por lo que resulta interesante apreciar el sesgo existente a la hora de valorar la utilidad del asociacionismo en función de si el joven está socializado en Cataluña o en el país de origen de los padres ${ }^{9}$.

Como resultado del proceso de socialización, pueden darse diversas situaciones en función de la forma en la que el joven asimila la cultura de acogida, y en cómo este hecho se adapta a su cultura de origen. Pese a que todavía es pronto para afirmar qué forma puede adoptar esta nueva cultura resultante, se puede intuir que va a presentar cambios respecto a las dos culturas en interacción, lo que permitirá al joven identificarse con ella desde un prisma de cultura juvenil.

[M, 17, Marruecos, soltera, grupo 2] Más que nada, porque los hijos van a la escuela, y en la escuela te dicen qué es el carnaval. Si fuera por los padres no lo celebrarían...

\footnotetext{
9 A pesar de lo comentado, las asociaciones de inmigrantes juegan un papel importante, aunque probablemente menguante a medida en que se consolida el movimiento migratorio. En este sentido, algunas entidades reorientan su función hacia la demanda del reconocimiento de derechos o incorporando jóvenes socializados en Cataluña para plantear actividades que incluyan los intereses de los jóvenes de segunda generación. En otros casos, la respuesta es la contraria, al incidir en la afirmación cultural de origen.
} 
[H, 22, Marruecos, soltero, grupo 2] La feria de abril, me gustaría que se hiciera aquí ...

p) ¿Si?

[H, 22, Marruecos, soltero, grupo 2] Es una pasada... un montón de peña... a mí me gusta, ¡eh!

p) Y a la fiesta mayor del pueblo, ¿también vais?

Todos. $\mathrm{Si}$

[H, 22, Marruecos, soltero, grupo 2] Es lo que más me gusta de (municipio)...

3.2.2 Identificación de las demandas en relación a la participación y las necesidades insatisfechas

Las demandas de los jóvenes de este grupo son asimilables a las de la población autóctona joven. El proceso de socialización común conlleva una creación pareja de necesidades y demandas por parte de los jóvenes autóctonos y de origen extranjero. En el joven de origen extranjero, su condición no es un impedimento para que solicite unas determinadas demandas, sino que son las condiciones sociales y económicas las que determinan el acceso a las oportunidades y los recursos y, sobre esta base, articulan las necesidades y demandas.

La principal demanda en relación con la participación social es que se facilite el acceso a las actividades que les interesan, lo que refuerza la actitud de técnicos y administraciones de intentar reducir el precio de las mismas. Este hecho genera actitudes dispares en la ciudadanía, en tanto que los esfuerzos de los técnicos para rebajar los precios son, en ocasiones, fuente de conflicto con los padres autóctonos, que ven una actitud paternalista para con la población inmigrada, que puede acceder a unas actividades públicas que acaban siendo únicamente para «pobres y extranjeros», mientras ellos deben concurrir al ámbito privado para realizar las mismas actividades.

Más allá de estas dificultades, las principales actividades demandadas por parte de los jóvenes socializados en Cataluña, equiparables a las de los jóvenes autóctonos, van asociadas al ocio y la formación ${ }^{10}$.

[Técnico] Los padres, los adultos, piden esto del recuerdo y las costumbres. Los jóvenes, no, los jóvenes, ocio y formación.

$10 \mathrm{El}$ asociacionismo vinculado al deporte constituye la tipología de asociacionismo más practicada en Cataluña según las diferentes encuestas realizadas entre la juventud catalana (el 33,6\% de los jóvenes entre 15 y 34 años afirman pertenecer a algún tipo de asociación deportiva) (VVAA, 2008). 
El deporte juega un papel importante, lo que traslada, de nuevo, una importante carga de actividades a escuelas e institutos, donde las actividades deportivas para niños y jóvenes alcanzan una notable presencia. Las actividades deportivas inciden en el mantenimiento físico y, por lo tanto, mejoran las condiciones de salud, a la vez que fomenta otras habilidades sociales como la cooperación o el trabajo en equipo. El principal problema que aparece en relación a las actividades deportivas es que la mayoría de edad supone un corte importante en relación a la oferta pública: existe mucha oferta para menores de 18 años, pero a partir de esta edad, su práctica regular se asocia al hecho de estar federado o formar parte de alguna entidad deportiva, lo que supone una progresiva desvinculación de los jóvenes en relación con estas actividades.

Por otro lado, la demanda de actividades formativas se debe a motivos instrumentales, en concreto a las dificultades que los jóvenes extranjeros socializados en Cataluña tienen para, una vez concluida la educación secundaria, proseguir su formación con el acceso a la Universidad u otros estudios de tercer grado, puesto que, más allá de las grandes ciudades, no existe una oferta suficiente para proseguir estudios. Además, la coyuntura económica, generalmente, no permite afrontar el gasto de una educación superior en otra ciudad. La demanda, pues, pasa por actividades formativas de especialización que faciliten el acceso a mejores lugares de trabajo.

Finalmente, en relación con la participación formal, los jóvenes socializados en Cataluña que han participado en algún proceso organizado por las administraciones son bastante críticos con su funcionamiento, lo que equipara su discurso al de los jóvenes autóctonos, inducidos, probablemente, por el suficiente conocimiento del territorio y sus formas de funcionar, así como por la conciencia respecto de sus posibilidades como ciudadanos.

[M, 18, Marruecos, soltera, grupo 2] y sirve lo que hablas, de lo que hablas? Luego la participación es muy importante pero si no sirve de nada... no sirve de nada luego hablar. Es que si hablas, así discutir y propones algo pero al final nada de eso se ve ¿para qué?

[M, 19, Marruecos, soltera, grupo 2] nos quieren motivar y no lo consiguen [M, 18, Marruecos, soltera, grupo 2] para motivar hay que ver hechos ¿no?

La demanda principal pasa por el hecho de que los procesos sean vinculantes, de modo que se complete el empoderamiento ciudadano que supone la participación y que, por lo tanto, las decisiones que se tomen en el mismo proceso tengan posibilidades de consolidarse. 


\subsubsection{Dificultades y fortalezas de la participación.}

La idea principal alrededor de las dificultades y fortalezas entre estos jóvenes tiene un considerable parecido con los elementos que dificultan la participación de los jóvenes catalanes. En primer lugar, las dificultades que se vinculaban con los jóvenes del grupo 1 pierden parte de su sentido en el caso de los jóvenes extranjeros socializados en Cataluña, en tanto que las dificultades idiomáticas quedan resueltas a partir del paso de los jóvenes por el sistema educativo, y las dificultades relacionadas con el acceso al trabajo disminuyen y son equiparables a las de los jóvenes autóctonos.

A pesar de estos elementos, la presencia de estos jóvenes en procesos de participación formal dista de ser la deseada y se necesita un mayor trabajo para visibilizar estos procesos y su utilidad. La sociedad catalana presenta numerosas realidades diferenciadas respecto a la cultura participativa en función de diversos factores, como pueden ser las condiciones de socialización, el hecho de que vivan en entornos urbanos o rurales, o la propia tradición. De todos modos, la percepción general es que la sociedad catalana también presenta lagunas importantes en la creación de conciencia participativa en los propios ciudadanos, lo que afecta, del mismo modo, a los jóvenes extranjeros socializados en Cataluña.

[Técnica] Ni estamos acostumbrados ni somos una sociedad que tengamos cultura participativa

[Técnica] No tenemos una cultura realmente de participación democrática. Yo creo que no...

Otro elemento que incide negativamente sobre la imagen que la ciudadanía tiene con respecto a los procesos de participación formal es la falta de concreción de muchos de estos procesos gestionados por parte de las administraciones. Esta percepción se asocia, en primer lugar, al hecho de que, en ocasiones, las personas que participan en los procesos de participación no alcanzan a entender sus límites o los objetivos que persiguen. En segundo lugar, la sociedad está acostumbrada a esperar los resultados de forma inmediata, y la participación, en relación a este asunto, presenta una importante demora en la generación de resultados inmediatos, lo que dificulta la percepción de utilidad de la participación ciudadana.

En relación con las fortalezas, el interés por la política, la gestión y la participación por parte de algunos de estos jóvenes abren un perfil muy interesante de cara a los próximos años a la hora de la gestión de la inmigración y su participación. La aparición de jóvenes socializados en Cataluña con esta inclinación por la gestión pública, así como los esfuerzos dedicados por parte de administraciones 
e instituciones educativas, permiten que se estén dando espacios específicos de formación en participación ciudadana y gestión del asociacionismo que deben hacer subir el nivel de calidad y exigencia de la misma.

\subsection{Grupo 3: Los jóvenes reagrupados durante la infancia y la juventud}

\subsubsection{Distinción de las formas de participación y conocimiento de los canales}

Existen dos elementos básicos que condicionan de forma general la relación de estos jóvenes con la participación: la edad con que se llega al territorio y la vivencia de las dificultades de sus progenitores a la hora de su integración social. El primero condiciona el acceso al sistema educativo, ya que aporta una desigual adquisición de las herramientas o habilidades que facilitan el acceso a la participación social. El segundo influye en la percepción individual acerca de la vivencia de la integración social y los esfuerzos que conlleva.

Esta combinación de factores coloca a los jóvenes reagrupados con posterioridad a los 10 años de edad en una posición intermedia entre los otros dos grupos objeto de la investigación, en tanto que pueden conocer, con mayor o menor intensidad, los canales de participación de los jóvenes extranjeros socializados en Cataluña y de la población autóctona, a la vez que conviven con las dificultades y canales de participación de los jóvenes con proyecto migratorio propio. Así, por ejemplo, en relación con el movimiento asociativo, estos jóvenes conocen sus funciones y potencialidades a pesar de que, en ocasiones, no se relacionan directamente con las entidades - labor que cumplen sus progenitores-, y su contacto con el mundo asociativo está relacionado con el consumo de actividades de ocio y de cultura demandadas por sus propios progenitores para mantener vivos sus respectivos referentes culturales.

En relación con el ámbito de la política, demuestran un conocimiento importante de las personas que dirigen la política en el ámbito estatal, pero decae en los ámbitos catalán y local. A este respecto, las trayectorias individuales dentro de las redes sociales locales determinan el interés y las posiciones políticas en un espacio en el que los referentes familiares se difuminan debido a la migración.

[H, 16, Bulgaria, soltero, grupo 3] (preguntado acerca de si a los jóvenes les interesa la política.) Yo. Sí, sí, yo conozco bastantes que sí, sí... hay un grupito, saben demasiado... (refiriéndose a jóvenes con inclinaciones políticas distintas a las suyas) 
3.3.2 Identificación de las demandas en relación a la participación y las necesidades insatisfechas

Las principales demandas constituyen también una combinación de las planteadas por los grupos anteriores. Entre los jóvenes extranjeros reagrupados recientemente que pertenecen a asociaciones, la reclamación acerca del derecho a la participación electoral es muy común, mientras que entre aquellos que no participan en las asociaciones, la vivencia familiar en relación con el proceso de acogida e integración les permite ser críticos con el papel de las mismas, para acabar lamentando las condiciones de acceso a las entidades y la escasa información que aportan.

[H, 19, Marruecos, soltero, grupo 3] Tú buscas por aquí una asociación y no la encuentras... yo no veo carteles, vienes aquí y no preguntas por una asociación...

p) Pero, por ejemplo, los rumanos, cuando llegan, enseguida reciben noticias de la asociación, ¿no?

[M 19, Rumanía, soltera, grupo 3] Sí...

[H, 19, Marruecos, soltera, grupo 3] Te enteras, pero no sabes donde está, y cuando necesitas ayuda, estos no te ayudan para nada...

Esta posición intermedia entre las dificultades de los progenitores y su conocimiento de la sociedad de acogida les lleva a ser, a menudo, intermediarios de las demandas de sus padres, adoptando un discurso ajeno pero vivido; citan, por ejemplo, las dificultades idiomáticas para la integración.

Finalmente, en relación con las tipologías de actividades demandadas, el ocio y la formación son, de nuevo, las más mencionadas, destacando el papel del deporte como actividad recurrente, a pesar de que se reiteran las dificultades en relación con la mayoría de edad, momento en el que las actividades deportivas disponibles se reducen de forma considerable.

\subsubsection{Dificultades y fortalezas de la participación}

Las dificultades comentadas anteriormente en relación con los jóvenes extranjeros con proyecto propio tienen validez para el análisis de este grupo, en función del momento de su llegada al territorio. Las dificultades idiomáticas y laborales fluctúan entre las comunes a las de los jóvenes autóctonos de clase baja-media y las de los jóvenes extranjeros con proyecto migratorio propio: constituyen una 
enorme dificultad para aquellos que no han podido aprender el idioma o para aquellos que llegan con una edad suficiente para trabajar. En relación con este hecho, las expectativas de vida también oscilan en función de la edad, en tanto que aquellos que llegan con edades más avanzadas expresan una mayor necesidad de trabajar, renuncian a la ampliación de los estudios como medida de promoción social y orientan sus esperanzas de futuro hacia el acceso al mercado laboral. El paso por el sistema educativo aporta, por otro lado, una visión más crítica con los sistemas de participación social, una vez disponen de un mayor conocimiento respecto de la sociedad de acogida.

Finalmente, cabe señalar que el papel de estos jóvenes en su entorno familiar también es cambiante; en unos casos constituyen el sustento económico, y en otros facilitan la mediación o la traducción de idioma. En este segundo caso, estos jóvenes cumplen una función social importante para la visibilización y transmisión de demandas concretas que, por motivos idiomáticos, quedarían ocultas. En el caso de que estos jóvenes-mediadores tengan familiares vinculados con las asociaciones, no resulta inusual que amplíen también su vinculación con las mismas, ampliando el rol de mediador/traductor del ámbito familiar al grupo de iguales, con lo que refuerzan su importancia en el colectivo y realizan una función importante para la integración.

[H, 25, Senegal, soltero, grupo 3]. A nosotros, yo creo que es una obligación, porque tú estás en nombre de la asociación, porque en la asociación siempre hacemos la reunión a final de mes, y después, si el presidente dice que estamos aquí en [municipio] y siempre trabajamos por la integración. Todas las actividades que harán el Ajuntament tenemos que participar.

\section{Conclusiones}

A modo de valoración general, cabe plantearse que la participación social de la población extranjera facilita la integración de ésta en la sociedad de acogida, pero que esta relación no se da a la inversa: la integración no conduce inevitablemente a la participación activa en la sociedad, sino que facilita la equiparación de actitudes con la población de acogida.

Entre la población joven de origen extranjero podemos establecer dos grupos claramente diferenciados entre aquellos que se han socializado mayoritariamente en Cataluña (grupo que engloba a los jóvenes extranjeros de segunda generación y los reagrupados que llegan en edades jóvenes), que presentan actitudes y valora- 
ciones hacia la participación social equiparables a las de los jóvenes autóctonos ${ }^{11}$, y los que llegan en edades que impiden su integración efectiva en el sistema educativo (grupo que incluye los jóvenes extranjeros con proyecto migratorio propio y los reagrupados que llegan con edades avanzadas), que presentan actitudes, valoraciones y condiciones individuales comunes que plantean dificultades para su normal participación social. Destaca, así pues, el papel cambiante de la población reagrupada en función de la edad con la que se produce.

\section{Gráfico 1. Comparación entre los tres grupos objeto de estudio.}

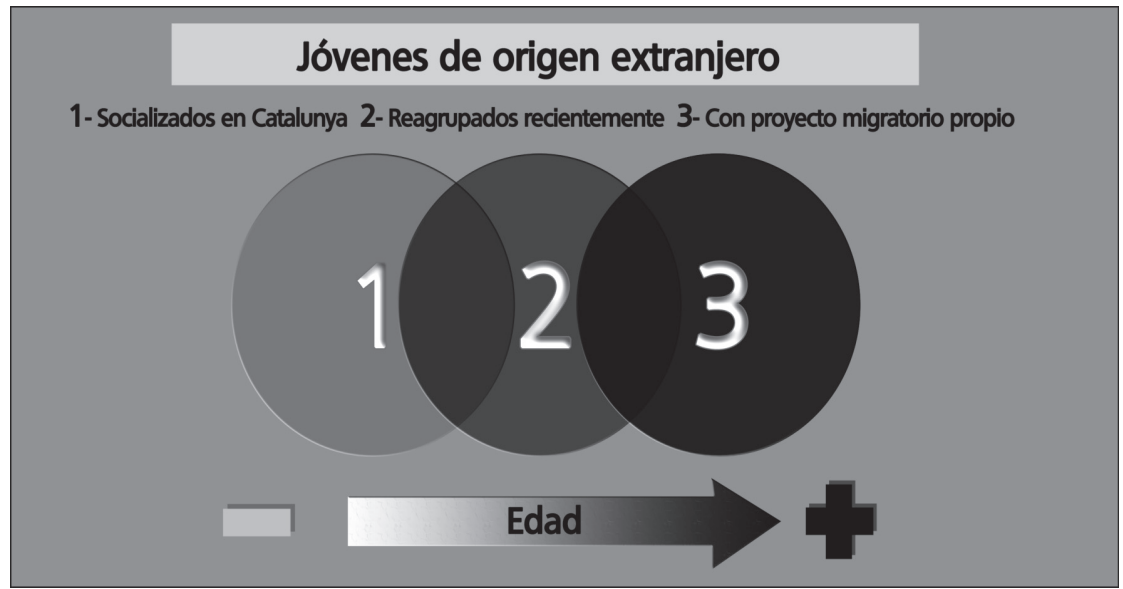

Fuente: Elaboración propia

En este sentido, las generalizaciones con respecto a la vinculación de la población de origen extranjero con la participación social deben ser revisadas teniendo en cuenta esta diferenciación, puesto que atribuye actitudes o comportamientos a las características del proceso migratorio, en lugar de a los orígenes culturales, identificando así posicionamientos comunes que vinculan a los individuos con la socialización de acogida. Esta socialización secundaria en el país de acogida genera modelos sociales diferenciales que trascienden las culturas de origen o, incluso, facilitan una revisión de los conocimientos adquiridos en el proceso de socialización primaria ${ }^{12}$ para aquellos jóvenes cuya socialización primaria se haya

11 Tanto el Sondeo sobre la juventud en España 2008 (Injuve, 2008) como la Enquesta a la joventut de Catalunya (VVAA, op.cit) ofrecen una visión similar a la planteada a lo largo del artículo: una juventud poco preocupada por la política y sus distintas derivaciones (participación social), pero sí por maximizar sus ingresos y vivienda y por consumir ocio, para la cual el asociacionismo deportivo constituye la modalidad asociativa con mayor aceptación, seguida, a mucha distancia, por el asociacionismo cultural.

12 Siguiendo la idea que Benedicto y Morán (2002) desarrollan a partir del pensamiento de Berger y Luckmann. 
dado en un contexto distinto al de acogida, añadiendo elementos que pueden condicionar la integración exitosa en la sociedad de acogida.

Las distintas realidades percibidas en relación con el momento de la inmigración plantean, así mismo, estrategias diferenciales en cuanto a la participación social en el mundo del asociacionismo: desde posiciones en las que la participación social constituye, mayoritariamente, una herramienta para el consumo de actividades de ocio o para el ascenso social (formación) individual — con el abandono de la lógica del bridging-bonding antes señalada ${ }^{13}$-, beneficiándose del papel mesosocial de las asociaciones, hasta posiciones opuestas en las que la participación social, mediante las asociaciones de inmigrantes, constituye un elemento para el mantenimiento de la cohesión social en el grupo de iguales (bonding) y para mediar para/y con la población de acogida y las instituciones (bridging).

En la misma línea, cabe apuntar que las dificultades para la participación social planteadas por Malgesini tienen una desigual incidencia en función del momento de la inmigración; son muy válidas para aquellos jóvenes socializados en otros países, pero presentan una incidencia menor para aquellos jóvenes que poseen una socialización desarrollada en el país de acogida o una socialización dual. Este elemento lleva a plantear una revisión de las dificultades o condicionantes anteriormente mencionados para los jóvenes de origen extranjero socializados en Cataluña, en tanto que la condición de «extranjero» pierde peso frente a otros elementos, como pueden ser la condición de «joven», el estatus socioeconómico o el nivel cultural de padres y madres, quedando el origen migratorio en una posición no tan decisiva en relación con el papel que el joven pueda desarrollar en el contexto de la participación social.

13 En tanto que el asociacionismo aparece como una herramienta que satisface necesidades y no como un elemento para la intervención política. 


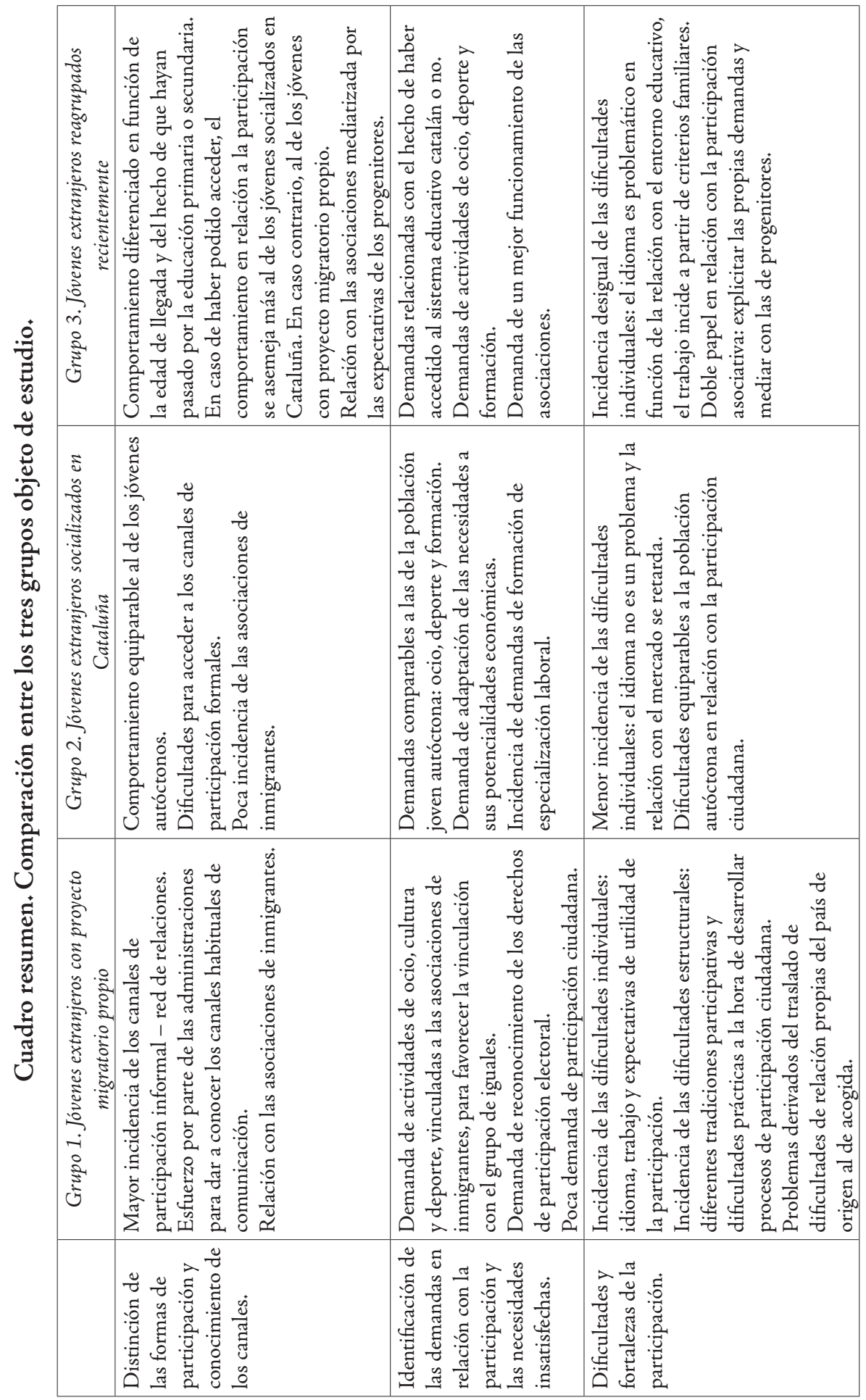




\section{Bibliografía}

Alarcón, A. (coord.) (2010). Joves d'origen immigrant a Catalunya. Necessitats $i$ demandes: una perspectiva sociológica. Barcelona: Secretaria de Joventut - Generalitat de Catalunya.

Alarcón, A.y Alcalde, R. (2010). The needs and demands of young people of immigrant origins in Catalonia: a sociological approximation. Barcelona: Secretaria de Joventut - Generalitat de Catalunya.

Benedicto, J. y Moran, Ma L. (2002). La construcción de una ciudadanía activa entre los jóvenes. Madrid: Injuve.

Boix, C. y Riba, C. (2000). «Las bases sociales y políticas de la abstención en las elecciones generales españolas: recursos individuales, movilización estratégica e instituciones electorales». Revista Española de Investigaciones Sociológicas, 90: 95-128.

Casey, J. (1998). «Les associacions i la integració d'immigrants estrangers». Revista Catalana de Sociologia, 6: 9-22.

Catт, H.(1999). Democracy in practice. New York: Routledge.

De Lucas, J. (2009). «Inmigración, diversidad cultural, reconocimiento político». Papers, 94: 11-27.

Delgado, I. (2010). «Elecciones municipales en España. Dimensiones analíticas y aspectos distintivos de ocho procesos electorales (1979-2007)». Política y Sociedad, 47:13-36.

Ganuza, E. y Francés, F. J. (2008). «¿A qué llamamos participar en democracia? Diferencias y similitudes en las formas de participación». Revista Internacional de Sociología, 49: 89-113.

Gonzalez, I. et alii (2007). Participació politica i joves. Una aproximació a les pràctiques polítiques, la participació social i l'afecció política de la joventut catalana. Barcelona: Secretaria de Joventut - Generalitat de Catalunya. (Colección Estudis, 22).

Hagan, J. et alii (1996). «New kid in town: Social capital and life course effects of family migration on children». American Sociological Review, 61 (3): 368-385.

Herzog, B. et alii (2009). «Identificación y solución de problemas para la participación ciudadana de los inmigrantes». Papers, 91: 45-64.

Injuve (2008). Informe de la juventud española 2008. Madrid: Instituto de la Juventud de España.

Justel, M. (1990). «Panorámica de la abstención electoral en España». Revista de Estudios Políticos, 68: 343-396. 
KwaK, N. et alii (2009). «Connecting, trusting and participating: The direct and interactive effect of social associations». Political Research Quarterly, 57 (4): 643-652.

Malgesini, G. (2007). «La participación de los jóvenes inmigrantes en el ámbito asociativo», en Cachón, L. et alii (2007). Juventud e inmigración. Desafíos para la Participación y la Integración. Dirección General de Juventud de la Consejería de Empleos y Asuntos Sociales del Gobierno de Canarias.

Martí, J. y Rebollo, O. (2007). Participació Ciutadana: bases, mètodes i tècniques. Barcelona: Diputació de Barcelona.

Moreras, J. (2009). Actors i representacions. L'associacionisme d'origen marroquí a Catalunya. Barcelona: Generalitat de Catalunya - Acció Social i Ciutadania.

Ortega, A.y Heredia, L. S. (2008). «El derecho al voto de los extranjeros en las elecciones municipales españolas. ¿Integración o interés?». Anuario Mexicano de Derecho Internacional, 8: 587-598.

Putnam, R. (2000). Bowling alone. New York: Free Press.

Serrano, J. y Sempere, D. (1999). La participación juvenil en España. Barcelona: Fundació Francesc Ferrer i Guardia.

Subirats, J. et alii (2007). Los servicios sociales de atención primaria ante el cambio social. Madrid: Ministerio de Trabajo y Asuntos Sociales.

VV.AA. (2008). Enquesta a la joventut de Catalunya. Barcelona: Generalitat de Catalunya.

Warren, M. E. (2001). Democracy and association. Princeton: Princeton University Press. En Montero, J. R. et alii (2006). Ciudadanos, asociaciones y participación en España. Madrid: Centro de Investigaciones Sociológicas. 